\title{
BMJ Open Use of out-of-hours primary care in affluent and deprived neighbourhoods during reforms in long-term care: an observational study from 2013 to 2016
}

\author{
Tessa Jansen, ${ }^{1}$ Robert A Verheij, ${ }^{1}$ Francois G Schellevis, ${ }^{1,2}$ Anton E Kunst ${ }^{3}$
}

To cite: Jansen T, Verheij RA, Schellevis FG, et al. Use of outof-hours primary care in affluent and deprived neighbourhoods during reforms in long-term care: an observational study from 2013 to 2016. BMJ Open 2019;9:e026426. doi:10.1136/ bmjopen-2018-026426

- Prepublication history for this paper is available online. To view these files, please visit the journal online (-2018026426">http://dx.doi.org/10. 1136/bmjopen-2018-026426).

Received 3 September 2018 Revised 11 December 2018 Accepted 21 January 2019

D Check for updates

(c) Author(s) (or their employer(s)) 2019. Re-use permitted under CC BY-NC. No commercial re-use. See rights and permissions. Published by BMJ.

${ }^{1}$ Department of Primary Care, Nivel, Netherlands Institute for Health Services Research, Utrecht, The Netherlands ${ }^{2}$ Department of General Practice \& Elderly Care Medicine, Amsterdam Public Health Research Institute Amsterdam University Medical Centers I Location VUmc, Amsterdam, The Netherlands

${ }^{3}$ Department of Public Health, Academic Medical Center (AMC), University of Amsterdam, Amsterdam, The Netherlands

Correspondence to

Tessa Jansen; t.jansen@nivel.nl

\section{ABSTRACT}

Objectives Major long-term care (LTC) reforms in the Netherlands in 2015 may specifically have disadvantaged socioeconomically deprived groups to acquire LTC, possibly impacting the use of acute care. We aimed to demonstrate whether LTC reforms coincided with changes in the use of out-of-hours $(\mathrm{OOH})$ primary care services (PCSs), and to compare changes between deprived versus affluent neighbourhoods.

Design Ecological observational retrospective study using routinely recorded electronic health records data from 2013 to 2016 and population registry data.

Setting Data from $1500 \mathrm{H}$ PCSs participating in the Nivel Primary Care Database (covering approximately 6.5 million inhabitants) in the Netherlands. PCS utilisation data on neighbourhood level were matched with sociodemographic characteristics, including neighbourhood socioeconomic status (SES).

Participants Electronic health records from 6120 384 00H PCS contacts in 2013-2016, aggregated to neighbourhood level.

Outcome measures and analyses Number of contacts per 1000 inhabitants/year (total, high/low-urgency, night/ evening-weekend-holidays, telephone consultations/ consultations/home visits). Multilevel linear regression models included neighbourhood (first level), nested within PCS catchment area (second level), to account for between-PCS variation, adjusted for neighbourhood characteristics (for instance: \% men/women). Differencein-difference in time-trends according to neighbourhood SES was assessed with addition of an interaction term to the analysis (year $\times$ neighbourhood SES).

Results Between 2013 and 2016, overall 00H PCS use increased by $6 \%$. Significant increases were observed for high-urgency contacts and contacts during the night. The largest change was observed for the most deprived neighbourhoods ( $10 \%$ compared with $4 \%-6 \%$ in the other neighbourhoods; difference not statistically significant). The increasing trend in $00 \mathrm{H} \mathrm{PCS}$ use developed practically similar for deprived and affluent neighbourhoods. A a stable gradient reflected more $00 \mathrm{H}$ PCS use for each lower stratum of SES.

Conclusions LTC reforms coincided with an overall increase in $00 \mathrm{H}$ PCS use, with nearly similar trends for deprived and affluent neighbourhoods. The results suggest a generalised spill over to $00 \mathrm{H}$ PCS following LTC reforms.

\section{Strengths and limitations of this study}

The large set of routine healthcare data enabled us to explore changes over time in out-of-hours primary care use, and to conduct multilevel analysis.

- The coverage of a substantial part of the Netherlands made generalisability of the findings to the national setting possible.

- Other developments, such as changes in the organisation of out-of-hours primary care services, may have affected patient flows and possibly influenced the study's findings.

- The use of socioeconomic status on neighbourhood level may have resulted in an underestimation of the influence of socioeconomic status on the outcome.

\section{INTRODUCTION}

In the prospect of ageing populations and emerging expensive technological opportunities, many Western countries are facing the challenge of increasing government expenditure on healthcare. ${ }^{1}$ The financial crisis from 2008 onward amplified the need to restructure public funding of healthcare systems. ${ }^{2}$ To keep the healthcare system affordable and sustainable, healthcare system reforms have been implemented in a number of these countries. ${ }^{3-5}$ Moreover, healthcare systems increasingly address self-reliance and individual autonomy of patients. ${ }^{67}$ Although equitable access to healthcare is one of the values addressed by the reforms, ${ }^{5}$ some healthcare system configurations may yield more equity than others in terms of accessibility. ${ }^{1} 8-10$ The question is whether specific healthcare reforms influence equity in access and use of healthcare services. Accordingly, with the Netherlands as case-study, we monitored whether healthcare system reforms coincided with changes in socioeconomic differences in healthcare use. More specifically, we studied the use of out-of-hours $(\mathrm{OOH})$ primary care services (PCSs) as low threshold care 
provider, before, during and after reforms in long-term care (LTC).

Provision of LTC was formerly regulated by the Exceptional Medical Expenses Act (AWBZ) and the Social Support Act (WMO). As of 1 January 2015, the AWBZ, concerning residential care and 24 hours home care, was replaced by the Long-term Care Act (WLZ). Non-residential care was partly transmitted to the Health Insurance Act (ZVW), and partly decentralised to municipalities regulated by the WMO. ${ }^{11}{ }^{12}$ In the Netherlands, LTC for elderly and disabled people concerned nearly one million people in 2014, of whom a quarter received residential care. ${ }^{12}{ }^{13}$ Specified to age groups, $30 \%$ of the patients eligible for LTC was younger than 50 years, $25 \%$ was between 50 and 74 years, $20 \%$ was 75 to 84 years and $25 \%$ of the patient was 85 years or older. ${ }^{14}$

The reform of LTC fitted in a larger restructuring and reorientation of the healthcare system with its origins in 2006. The role of the central government gradually diminished, resulting in decentralisation of responsibility for the provision of mental healthcare, youth care, and LTC to the municipalities in 2014 and 2015. ${ }^{11}{ }^{12}$ Restructuring LTC for elderly and disabled people in 2015, was mainly intended to provide efficient patient-tailored care, while simultaneously saving on healthcare expenditures. ${ }^{11} 12$ The LTC reforms consisted of four major measures: First, patients have to be self-reliant and primarily receive informal care from their social network. Second, LTC shifted from residential to non-residential care: people are currently only eligible for long-term institutional care if they need constant care and supervision. People with minor health conditions receive informal and formal home care as long as possible. Thirdly, the provision of non-residential care has been decentralised to municipalities to enable the organisation of social and medical services closer to the patient's home. And fourthly, LTC expenditure reductions were used as an austerity measure. $^{1215}$

The reforms were issued under the assumption that people were willing and able to take up a more active role in managing their health and healthcare needs, and for instance mobilise their social network to provide care. ${ }^{61216}$ The assumed active role of patients in need of LTC may however specifically disadvantage people from lower socioeconomic backgrounds. Low socioeconomic status (SES) is related to worse health and more prevalent multi-morbidity, which in addition onsets at earlier age. $.^{9} 17-19$ Several conditions related to vulnerability of low SES patients, for example, financial strain and poor health behaviour, often cluster together, complicating the patients' circumstances even more. ${ }^{1820-22}$ Consequently, when vulnerable people are faced with the complexity of the LTC system and an appeal is made to their self-reliance, they may instead turn to easily accessible acute care services, such as an emergency department (ED) or an OOH PCS. ${ }^{23}{ }^{24}$ Alternatively, a group of frail people may develop, who would benefit from LTC, but who do not meet the eligibility criteria for LTC. ${ }^{25}$ If they are unable to obtain appropriate and timely formal and informal care, they may end up in unplanned acute care if their health condition worsens. ${ }^{26} 27$

Our goal was to retrospectively study whether the LTC system reform coincided with changes in OOH PCS use. Moreover, we aimed to explore whether trends in the use of these services developed differently in deprived versus affluent areas, as indicator for (in)equity in healthcare provision. We assumed that possible increase in of $\mathrm{OOH}$ PCS use could indicate a spill over effect due to inadequate provision of LTC. Accordingly, we hypothesised (1) that between 2013 and 2016 the number of contacts with an OOH PCS increased, and (2) that the relative increase OOH PCS use was larger in deprived areas as compared with more affluent areas.

To gain more understanding about the nature of developments in the use of OOH PCSs, we additionally explored whether trends in the urgency of the contacts, the time the contact took place and the type of contact, differed for deprived and affluent areas. Differences in trends may indicate changes in the (perceived) severity of the health problem and need to contact an OOH PCS. For instance, a large portion of contacts with an $\mathrm{OOH}$ PCS is not urgent from a medical perspective and may reflect more patient-related motives, such as worry and need for information. ${ }^{28}{ }^{29}$ Supposedly, these motives come into play more often in contacts during the early evening and daytime in the weekend, whereas people during the night more likely contact an OOH PCS due to medically acute health problems. Additionally, the type of contact follows from the urgency-assignment and may indicate severity of the health problem. Home visits and consultations generally reflect higher severity than telephone consultations. ${ }^{30} 31$

In the Netherlands, acute (somatic) healthcare is provided by emergency ambulance services and EDs of hospitals for life-threatening health conditions, specialist care and/or advanced diagnostics. Additionally, acute care for non-life threatening health problems is provided by general practitioners (GPs) ${ }^{32-34}$ Similar to the UK and Denmark, during $\mathrm{OOH}$, low-threshold care for health problems that cannot wait to be attended to until the next working day of someone's own GP, is provided by OOH PCSs. ${ }^{35} 36$ In 2016, the volume of acute care use in the Netherlands involved 500000 direct entries at the ED, 1 million emergency ambulance deployments and 4.2 million contacts with an OOH PCS. ${ }^{37}$ This study focused on care provided by OOH PCSs only.

The majority of PCSs provide care during all $\mathrm{OOH}$, including evening hours from 17:00 to 00:00 hours, night/early morning hours from 0:00 to 08:00 hours, and during all hours in the weekend and holidays. ${ }^{30} 33$

\section{METHODS}

Setting

Patients are supposed to contact the PCS by telephone (about $10 \%$ of the patients visits the PCS unannounced ${ }^{38}$ ), 
after which the severity of their health problem is assessed by a trained triage nurse. Supported by a computer assisted triage system, the nurse determines the urgency level and decides what follow-up the patient needs. Follow-up by the PCS includes: telephone advice from the triage nurse or GP by phone, consultation at the PCS practice, or the GP visits the patient at home. Alternatively, patients are referred to an ambulance for transport to an ED of their healthcare need is too serious to be attended to by the OOH PCS. ${ }^{33} 3839$

\section{Study design}

This ecological observational retrospective study used routinely recorded electronic health records data. The use of routine healthcare data allowed us to explore longitudinal patterns in OOH PCS use, without burdening healthcare providers with additional administration. Due to the coverage of a substantial part of the Netherlands, generalisability of the findings to the national setting is possible. In addition, the large dataset allowed to conduct multilevel analysis to control for organisational differences. We used registry data of claimed contacts from PCSs participating in Nivel Primary Care Database. ${ }^{40}{ }^{41}$ Data were anonymised by a trusted third party to secure privacy of patients, ${ }^{42}$ and cannot be traced back to individual patients.

We used health records data on the aggregate level of neighbourhood from 2013 to 2016 (1 January 2013-31 December 2016) from 15 PCSs. The eligible study sample covered 1271 neighbourhoods (1272 in 2016, due to reclassification of one area to another municipality), covering approximately 6.6 million inhabitants (39\% of the Dutch population). Neighbourhoods that were serviced by more than one PCS (approximately $3 \%$ of the neighbourhoods), were included in the analyses using a weighting factor. Data of 304742 contacts (nearly 5\%) were excluded from the analyses for patients whose neighbourhood was unknown or who resided in a neighbourhood outside the catchment area of the PCS (for instance when a patient visited a PCS during holidays outside their own region). Consequently, the pooled data for 4 years included 6120384 contacts. Excluded contacts differed from included contacts with regard to age and gender (more men, considerably more within age group 18-44 years), and the type of contact (more face-to-face consultations). Contacts did not pronouncedly differ with regard to urgency and time of the contact. Although LTC mainly involves care to elderly, a substantial share includes individuals of 50 years and younger. Consequently, our analyses included OOH PCS contacts of all age-groups.

\section{Patient and public involvement}

Patients and public were not directly involved in this study.

\section{Measures}

Outcome measures

We calculated the use of a PCS by (a) the number of PCS contacts in the observation year (numerator) per 1000 inhabitants of the neighbourhood (denominator).
Subsequently, we differentiated the volume of PCS use by time of contact: (b) during the night (00:00-08:00 hours) and (c) in the evening and weekends (17:00-00:00 hours, and during the day on Saturday, Sunday and holidays); and by urgency of the contact: (d) high urgency and (e) low urgency. The urgency level of the contact was categorised as highly urgent for levels U0 (resuscitation), U1 (life-threatening), U2 (acute) and U3 (urgent). Accordingly, low urgency contacts included urgency levels U4 (non-urgent) and U5 (self-care advice). ${ }^{39}$ Additionally, we differentiated the type of contact with the PCS: (f) home visit, (g) consultation at the PCS practice and (h) telephone consultation.

\section{Independent variables}

Change in time: we assessed the change over time per year (2013-2014 - 2015-2016), taking 2013 as baseline or index year.

Neighbourhood SES: SES scores on neighbourhood level were derived from The Netherlands Institute for Social Research. ${ }^{43}$ Scores were used from the measurement year 2014 and kept constant for all years. This measure is a commonly used indicator for SES of neighbourhoods in the Netherlands, and reflects the social status of a neighbourhood compared with other neighbourhoods. The score was derived from mean neighbourhood income, percentage of neighbourhood inhabitants with low-income, percentage of low-educated inhabitants and percentage of inhabitants without a job. Status scores were categorised in quartiles, based on the status score distribution of all neighbourhoods in the Netherlands. ${ }^{44}$

\section{Confounders}

Characteristics of neighbourhoods' demographic composition, including age, sex and degree of urbanisation, were derived from population registry data from Statistics Netherlands. ${ }^{45}$ For each year, we matched these characteristics of the year of concern. Age was categorised in groups: 0-4 years, 5-17 years, 18-44 years, $45-64$ years, 65-74 years, 75-84 years and 85 years and older. Level of urbanisation was categorised in five groups and ranges from rural $\left(<500\right.$ addresses $\left./ \mathrm{km}^{2}\right)$ to very strongly urbanised $\left(>2500\right.$ addresses $\left./ \mathrm{km}^{2}\right){ }^{4546}$

\section{Statistical analyses}

We first conducted descriptive analyses to describe the data. Subsequently, we applied multilevel linear regression models to analyse associations between PCS use (for all outcomes: $\mathrm{a}-\mathrm{h}$ ) and year. No multicollinearity was found for confounding variables and neighbourhood status, reflected in a variance inflation factor of well below 2.0 assessed with a general linear model. The multilevel structure of the models accounted for clustering of the data within catchment areas of PCSs, and contained two levels: neighbourhood (first level), and PCS catchment area (second level). We used the restricted maximum likelihood method, using an unstructured variance/covariance matrix to account for autocorrelation between years. 
Table 1 Sociodemographic composition of the population in the PCS catchment areas, and out-of-hours PCS use in number of contacts/1000 inhabitants per year

\begin{tabular}{|c|c|c|c|c|c|}
\hline \multirow[b]{2}{*}{ Year } & \multicolumn{4}{|l|}{ Sample } & \multirow{2}{*}{$\begin{array}{l}\begin{array}{l}\text { Dutch } \\
\text { population }\end{array} \\
2016\end{array}$} \\
\hline & 2013 & 2014 & 2015 & 2016 & \\
\hline \multicolumn{6}{|l|}{ Area composition } \\
\hline & 6549261 & 6570960 & 6599953 & 6631441 & 16977556 \\
\hline Number of inhabitants & $\%$ & $\%$ & $\%$ & $\%$ & $\%$ \\
\hline Female & 50.2 & 50.1 & 50.1 & 50.1 & 50.4 \\
\hline Age group 0-4 years & 5.2 & 5.1 & 5.1 & 5.0 & 5.2 \\
\hline $5-17$ years & 15.6 & 15.5 & 15.3 & 15.2 & 15.0 \\
\hline 18-44 years & 33.2 & 32.8 & 32.3 & 32.0 & 33.5 \\
\hline $45-64$ years & 29.1 & 29.2 & 29.4 & 29.5 & 28.2 \\
\hline $65-74$ years & 9.9 & 10.3 & 10.6 & 10.9 & 10.5 \\
\hline 75-84 years & 5.2 & 5.3 & 5.4 & 5.5 & 5.6 \\
\hline $85+$ years & 1.8 & 1.9 & 1.9 & 2.0 & 2.1 \\
\hline Urbanisation rural & 38.4 & 38.5 & 37.9 & 37.7 & 50.2 \\
\hline Low & 15.5 & 15.2 & 14.4 & 14.2 & 13.8 \\
\hline Moderate & 13.6 & 13.9 & 12.7 & 13.0 & 11.3 \\
\hline High & 17.2 & 16.9 & 18.7 & 18.8 & 14.8 \\
\hline Very high & 15.3 & 15.6 & 16.3 & 16.4 & 10.0 \\
\hline Neighbourhood SES very low & 24.5 & 24.5 & 24.5 & 24.6 & 25.0 \\
\hline Low & 20.5 & 20.5 & 20.5 & 20.5 & 25.0 \\
\hline High & 23.4 & 23.4 & 23.4 & 23.3 & 25.0 \\
\hline Very high & 31.6 & 31.6 & 31.6 & 31.5 & 25.0 \\
\hline PCS use/1000 inhabitants & $\bar{n}$ & 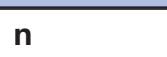 & $\mathbf{n}$ & $\mathbf{n}$ & $\mathbf{n}$ \\
\hline Contacts total & 219.1 & 215.8 & 221.7 & 232.9 & - \\
\hline Urgency high & 115.7 & 116.3 & 125.2 & 136.4 & - \\
\hline Low & 103.3 & 99.5 & 96.4 & 96.5 & - \\
\hline Time night & 26.2 & 26.5 & 27.6 & 29.5 & - \\
\hline Evening/weekend/holiday & 192.8 & 189.4 & 194.1 & 203.3 & - \\
\hline Type of contact home visit & 23.5 & 22.6 & 22.7 & 22.9 & - \\
\hline Consultation & 106.5 & 107.5 & 111.1 & 116.6 & - \\
\hline Telephone consultation & 89.0 & 85.7 & 87.8 & 93.4 & - \\
\hline
\end{tabular}

PCS, primary care service; SES, socioeconomic status.

To assess whether the trend in PCS use differed between deprived and affluent neighbourhoods, we conducted a difference-in-difference analysis by adding the interaction term year * neighbourhood status to the models similar to Cookson et al. ${ }^{47}$ All models were adjusted for demographic composition of the neighbourhood. We used the mixed function in Stata V.14.0. ${ }^{48}$ CIs were set at $95 \%$.

\section{RESULTS}

\section{Characteristics of the sample}

Table 1 pictures the demographic composition of the population in the catchment areas of the PCSs included in our study, compared with the general Dutch population in 2016. The sample approximately resembled the
Dutch population according to age and sex, however under-represented rural neighbourhoods, and overrepresented (very) highly urbanised neighbourhoods. Additionally, our sample included considerably more very high-SES neighbourhoods and fewer high and low SES neighbourhoods. Our data included regions in the centre of the Netherlands, including the mid-West and mid-East, and the North.

\section{Trend in use of 0OH PCS 2013-2016}

The use of OOH PCS increased between 2013 and 2016. Table 1 demonstrates that the mean number of contacts per 1000 inhabitants increased between 2013 and 2016, except for a decline in 2014. The mean number 
of contacts showed an overall increase, aside from low urgency contacts and home visits. Whereas the total volume of PCS use increased with $6.3 \%$, the number of high urgency contacts increased with almost $18 \%$. Meanwhile, the number of low urgency contacts diminished with almost $7 \%$.

As reflected in table 2, the yearly increase in total number of contacts was not statistically significant after controlling for sociodemographic characteristics of the neighbourhoods and the differences associated with OOH PCS (the random effect in the model). The number of high-urgency contacts and contacts during the night was significantly higher in 2015 and 2016 compared with 2013. In contrast, the number of low-urgency contacts and home visits significantly decreased, although the difference between 2013 and 2016 was not statistically significant. Additionally, adjusted for all other factors, table 2 shows that the number of contacts over the full spectrum of outcomes significantly differed between deprived and affluent neighbourhoods. In every year a gradient was observed with more OOH PCS use for each lower stratum of neighbourhood SES.

\section{Differences in time trends between deprived and affluent neighbourhoods}

In table 3 , the changes over time per stratum of neighbourhood SES are depicted. The proportions indicate the change in predicted mean number of contacts $/ 1000$ inhabitants compared with the baseline-year 2013. The mean number of contacts was predicted based on multilevel regression models adjusted for neighbourhood demographic composition, differences between PCSs and the interaction between year and neighbourhood SES. OOH PCS use in the lowest SES neighbourhoods was substantially higher for all outcomes, and all years, compared with the other neighbourhoods. Moreover, the changes between 2013 and 2016 were somewhat more pronounced for the lowest SES neighbourhoods. The predicted mean number of total contacts between 2013 and 2016 increased with $10 \%$ for very low SES neighbourhoods compared with a $4 \%-6 \%$ increase for low to very high SES neighbourhoods. The time trends for all outcomes did not statistically significant differ between deprived and affluent neighbourhoods, as is reflected in the difference-in-difference (table 3). Some statistically significant interaction between year and neighbourhood SES was observed for high-urgency contacts, indicating a lower increase in high urgency-contacts for higher SES neighbourhoods. Nevertheless, the interaction between year and SES appeared to only marginally affect overall OOH PCS use. Additionally, the time trends in predicted mean number of contacts/1000 inhabitants are illustrated in figure 1. Correspondingly, the graphs show that the increase in OOH PCS use between 2013 and 2016 developed nearly parallel between deprived and affluent neighbourhoods, for each stratum of SES.

Additionally, we conducted a post-hoc subgroup analysis to explore whether outcomes as reported in table 3 differed for the age group of 75 years and older. We however did not find actual differences between the whole group analysis and the subgroup of 75 years and older, as is depicted in see table 4 .

\section{DISCUSSION \\ Main findings}

In the past decade, subsequent Dutch administrations issued policy reforms that emphasise individuals' self-reliance and gradually reduced government support. ${ }^{6} \mathrm{We}$ aimed to explore whether the reforms of LTC care may have affected care provision to lower socioeconomic groups. We assumed that $\mathrm{OOH}$ primary care as low threshold healthcare provider could serve a sentinel function to detect inadequate long-term healthcare provision. Therefore, we monitored whether the reform in the provision of LTC coincided with changes in the use of OOH PCSs. Our results indeed showed an increase between 2013 and 2016 in yearly number of contacts. Moreover, this increase was statistically significant for high-urgency contacts, and contacts during the night, while the number of low-urgency contacts declined in the same period.

However, we found that the changes did not develop differently in deprived versus affluent neighbourhoods. Although our results indicated a gradient with more contacts in deprived compared with affluent neighbourhoods, we did not find statistically significant differences in the extent of increased OOH PCS use between 2013 and 2016.

\section{Study limitations}

Some issues have to be taken into account in the interpretation of the study's findings. Since the amendment of LTC, alike other policy changes, did not occur in a controlled experimental setting, obviously we were unable to control for the potential effect of other reforms. Parallel to LTC reforms, other healthcare system reforms and macro developments have occurred (eg, Thomson et al, ${ }^{2}$ for which it is impossible to visualise underlying trends in data of only 4 years. The follow-up time of our study therefore is too limited to determine whether the observed trend is persistent and logically followed from the reforms. Therefore, monitoring should be prolonged for a longer time-period after healthcare system reforms. ${ }^{15}$ Moreover, generally a time lag is to be expected between policy changes and changes in healthcare use and outcomes. ${ }^{154}$ Consequently, our study's exploratory nature should be valued as a starting point in the evaluation of the consequences of the LTC reforms on OOH PCS use.

Furthermore, before and during the period of the LTC reforms, changes in the organisation of $\mathrm{OOH}$ PCSs have occurred. For instance, more than half of the OOH PCSs integrated with a hospital ED and triage quality assessment was implemented in $2016 .{ }^{33}$ We were not able to control for possible effects of organisational changes on patient flows. Possibly, the increases in contacts followed 


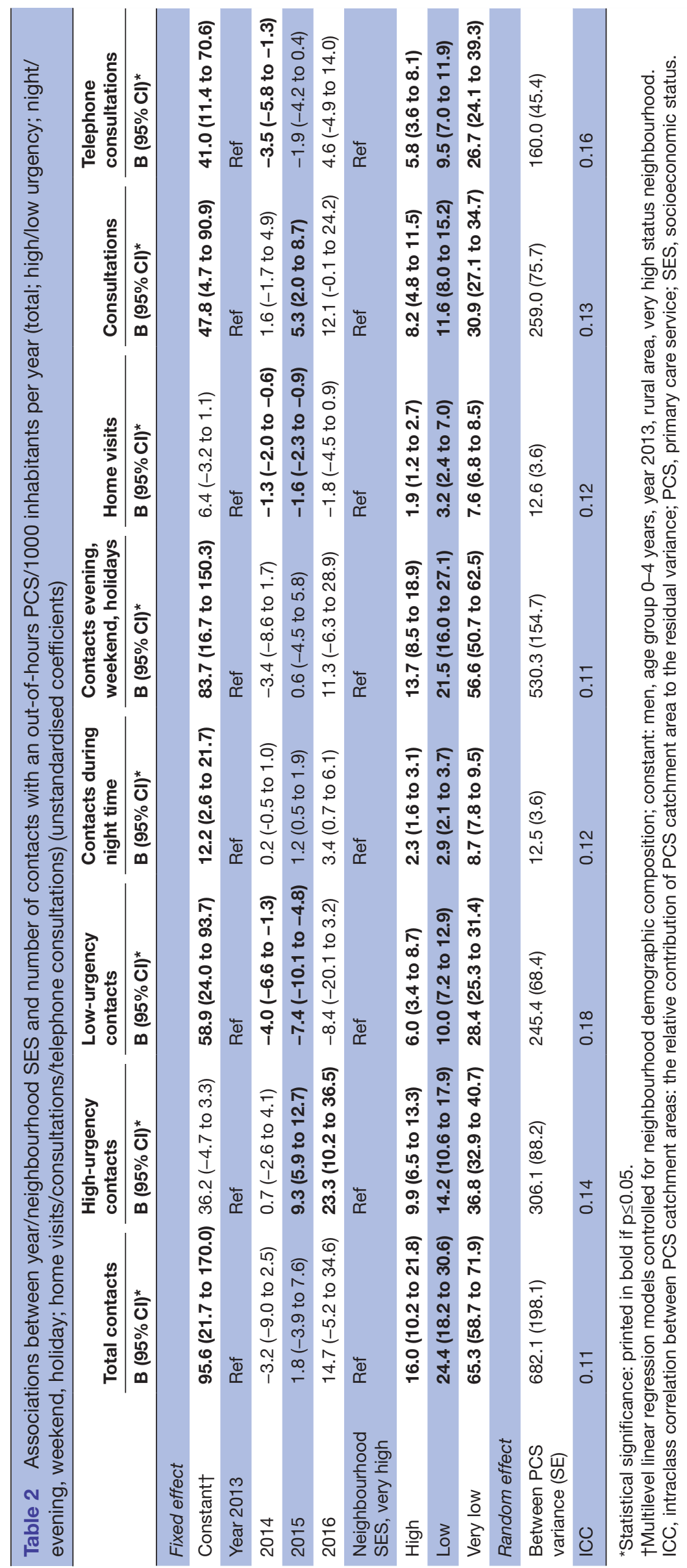




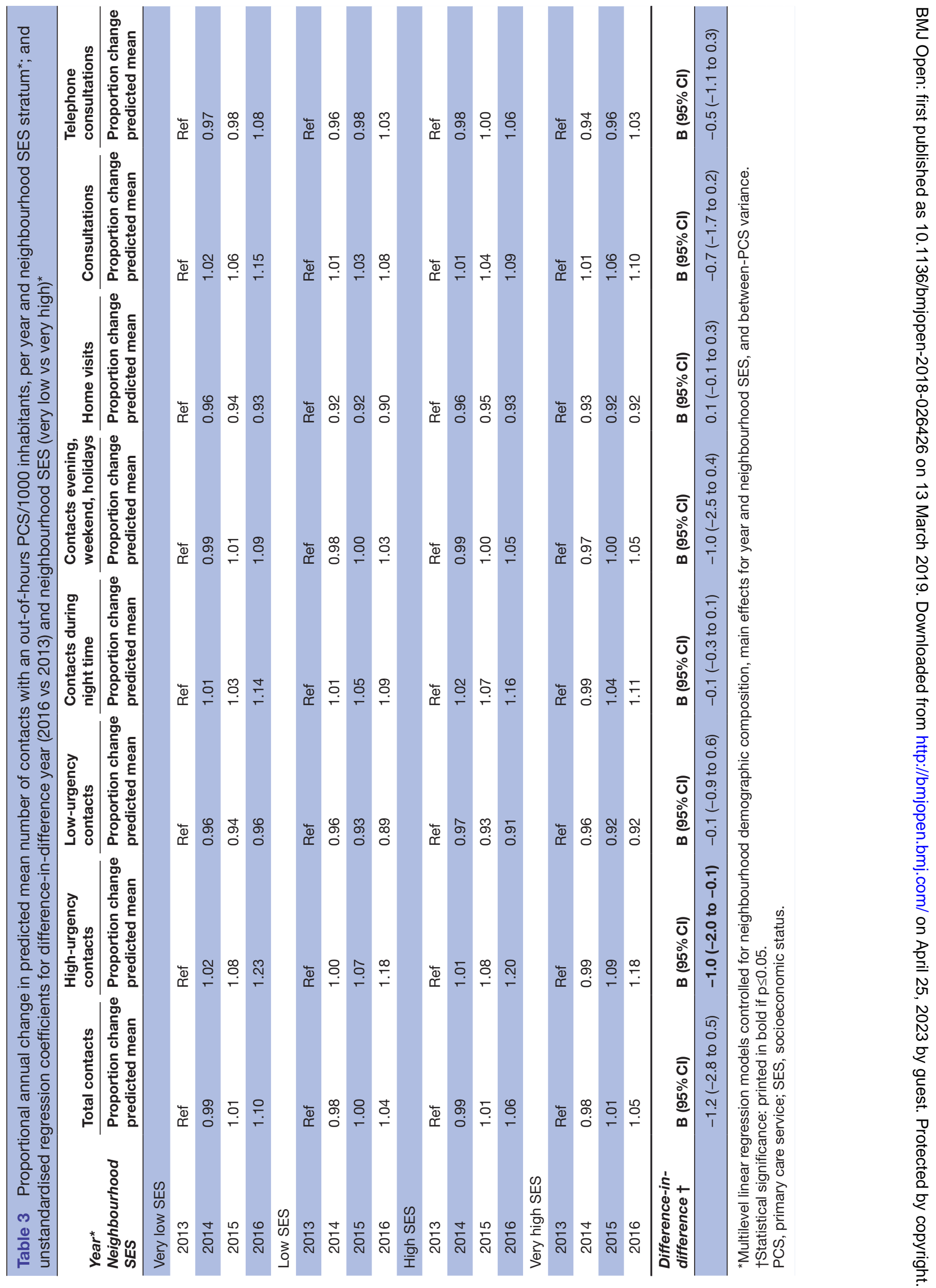



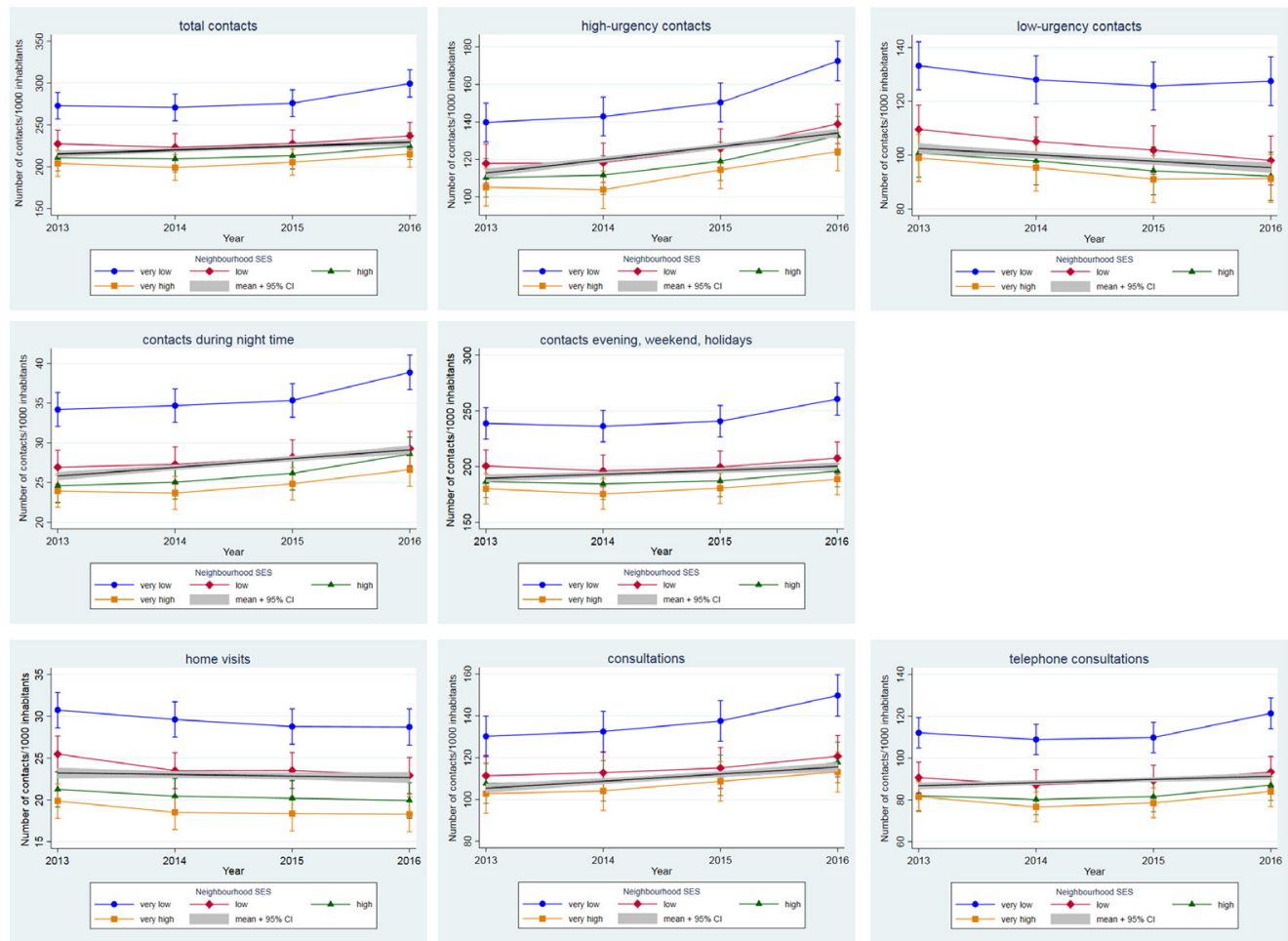

Figure 1 Time trends in predicted mean number of contacts with an out-of-hours primary care service by neighbourhood socioeconomic status (SES) quartile and overall mean/1000 inhabitants (total; high/low urgency; night/evening, weekend, holiday; home visits/consultations/telephone consultations), 95\% Cls.

from shifts from the ED to OOH PCSs. ${ }^{33}$ However, these organisational changes are unlikely to have influenced OOH PCS provision differently for deprived neighbourhoods compared with more affluent neighbourhoods.

To determine whether $\mathrm{OOH}$ PCS use changed due to the LTC reforms, we ideally would have added to the analysis a control country with a similar OOH PCS system but no LTC reforms. However, it was not feasible within the scope of this study to conduct such a country controlgroup comparison.

Another limitation is the classification of SES. Since our main independent variable was only available to us on the neighbourhood level, we limited our analyses to administrative neighbourhoods instead of smaller areas or individual level. ${ }^{50}$ Consequently, the trends we observed indicate associations on the neighbourhood level and should not be attributed to individuals, to avoid the pitfall of ecological fallacy. ${ }^{51}{ }^{52}$ The ecological approach of our study therefore did not allow us to state conclusions about individual patients and the chance of patients with low SES versus patients with high SES to use an OOH PCS.

\section{Interpretation of key findings}

The upward trend in $\mathrm{OOH}$ PCS use we observed in the present study is undeniable. Moreover, the increase in OOH PCS use we observed in 2015 and 2016, departed from a downward trend between 2009 and 2014. ${ }^{30}$ Although other possible factors could have been responsible for increased use of $\mathrm{OOH}$ care, for instance the development of 24 hours service economy, risk-adversity or better accessibility, ${ }^{29}$ these are not solely applicable to the period of our study. Furthermore, seasonal influenza epidemics possibly explains some of the variation in healthcare utilisation over time. For acute respiratory infections and influenza like illness, the consultation rates in general practice where higher in the influenza season $2014 / 2015$, compared with the season $2015 / 2016 .^{53}$ Likely, the number of contacts with an $\mathrm{OOH}$ PCS was affected by the seasonal influenza epidemic as well.

The increase of OOH PCS use that we found could indicate more desirable allocation of healthcare resources, which might be reflected in the pronounced increase in high-urgency contacts in favour of low-urgency contacts, and a sharper increase of contacts during the night. At the same time, the use of emergency care, including ambulance services, increased as well, ${ }^{37}$ just as healthcare use in general practice during office hours. ${ }^{54}$ Therefore, OOH PCS use appeared not to substitute, but to surplus use of these other healthcare services.

Our finding that the increase in OOH PCS use did not differ between deprived and more affluent neighbourhoods indicate that inequity in the accessibility of $\mathrm{OOH}$ healthcare remained stable between 2013 and 2016. The (perceived) threshold for attaining LCT and contacting an OOH PCS seemingly changed similarly for deprived and more affluent neighbourhoods. Two recent studies found that part of the people in need of LTC are not able to 


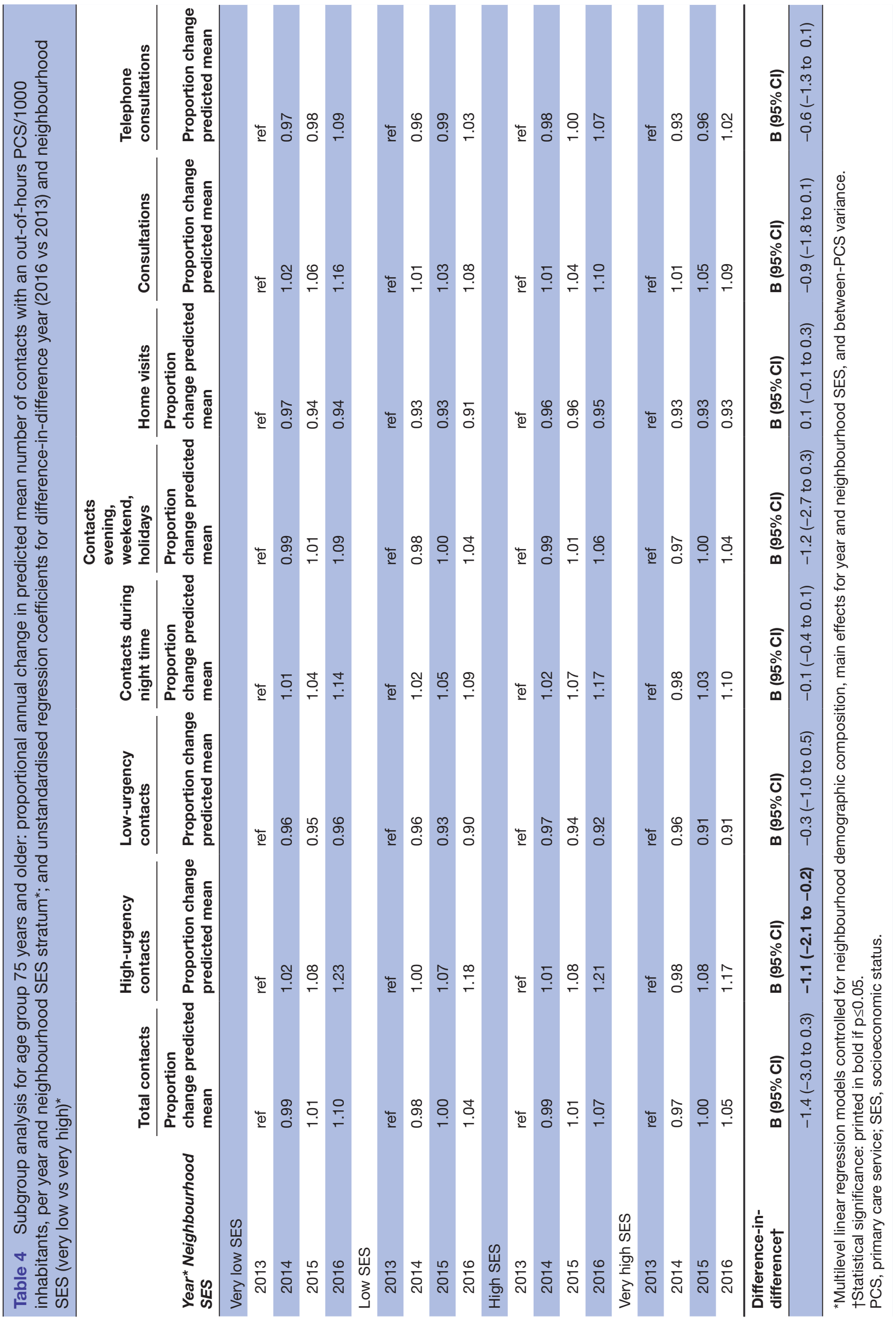


obtain care, and experience difficulty in finding the way to adequate support. ${ }^{1555}$ Based on our findings these observations appear to equally apply to all socioeconomic groups.

Notably, we observed the largest differences in increased OOH PCS use between the most deprived neighbourhoods compared with the other strata, although not statistically significant. The majority of the most deprived neighbourhoods are located in very strongly urbanised areas, generally inhabited by larger populations of non-Western immigrants. They tend to use $\mathrm{OOH}$ PCSs more often than native Dutch, ${ }^{56}$ and may experience more difficulties in obtaining LTC due to language barriers and limited health literacy. ${ }^{57}$

\section{Implications for research and practice}

The increased OOH PCS use between 2013 and 2016 may well be relevant in terms of workload. An increase of about $6 \%$ in total volume of contacts, and an increase of about $18 \%$ in high-urgency contacts undoubtedly affects the workload and raises planning and staffing issues. Low-urgency contacts could be handled by phone or a consultation with a GP without a narrow time-slot, whereas high-urgency contacts have to be attended to immediately, or at least within a few hours by a GP. ${ }^{33}$ Moreover, high-urgency contacts suggest more complex healthcare needs, and more follow-up in administrative workload, for instance referral to secondary care. ${ }^{58}$

The general increase in OOH PCS use we observed is beneficial if it substitutes emergency services, however is worrying when it is additional to other acute care services, or substitutes LTC. One could argue that a patient eventually receives the care when it is needed, though it is in an acute care-setting instead of regular care. Nonetheless, when acute care substitutes for regular care, as provided in LTC, patients might be worse off due to a lack of continuity of care, lack of background knowledge regarding the patient ${ }^{58}$ healthcare providers working under the inevitable pressure of an acute care-setting and an increasing workload conflicting the quality of care. ${ }^{35} 5960$ Moreover, patients with multi-morbidity typically benefit from continued care and prolonged relations with healthcare providers, while fragmented care may be harmful due to its focus on single health conditions. ${ }^{1961}$

Since sustainable LTC is an important issue in numerous countries, ${ }^{4}$ future research is justified to monitor the impact of reforms on equitable access to LTC. $^{62}$ Moreover, healthcare reforms should focus not only the effects on the direct objectives of the reforms, but also consider unintended effects such as spill over effects, specifically among vulnerable populations.

\section{CONCLUSION}

The use of OOH PCSs substantially increased between 2013 and 2016, at the time that LTC reforms were implemented. This occurred to the same extent in deprived and affluent neighbourhoods, suggesting an equitable potential impact of LTC reforms. The generalised increase suggests a spill over in need of unplanned care as provided by OOH PCSs after the period of the reforms. Evidently, the general increase in volume of $\mathrm{OOH}$ primary care use and additional increase in high-urgency contacts burdens $\mathrm{OOH}$ PCSs, and challenges sustainable $\mathrm{OOH}$ care provision.

Acknowledgements The authors like to thank the Primary Care Cooperatives for participating in the Nivel Primary Care Database. We would like to thank Lucas S van der Hoek and Bart van den Borne for their advice concerning the statistical analysis.

Contributors TJ designed the study, performed the statistical analyses and wrote the manuscript. RAV, FS and AK supervised the study and statistical analyses, and adapted the manuscript. All authors read and approved the final manuscript.

Funding The data of this study were collected within the research infrastructure 'Nivel Primary Care Database', which is funded by the Netherlands ministry of Public Health, Welfare and Sports. The funder had no role in the analyses and interpretation of the data.

Competing interests None declared.

Patient consent for publication Not required.

Ethics approval This study does not fall within the scope of the Medical Research Involving Human Subjects Act and therefore does not require ethical approval. PCSs that participate in Nivel Primary Care Database are contractually obliged to: (1) inform their patients about their participation in Nivel Primary Care Database, and (2) to inform patients about the option to opt-out if patients object to inclusion of their data in the database 42. Dutch law allows the use of electronic health records data for research purposes under certain conditions. According to Dutch legislation, and under certain conditions, neither obtaining informed consent nor approval by a medical ethics committee is obligatory for this kind of observational studies (Dutch Civil Law (BW), Article 7:458; http://www.dutchcivillaw.com/civilcodebook077.htm, Medical Research Involving Human Subject Act (WM0); http://www.ccmo.nl/en/nonwmo-research), and General Data Protection Regulation (AVG) Article 24 (GDPR)).

This study has been approved by the applicable governance bodies of Nivel Primary Care Database under no. NZR-00316.011.

Provenance and peer review Not commissioned; externally peer reviewed.

Data sharing statement The unpublished raw data files and statistical code are available upon request from the authors.

Open access This is an open access article distributed in accordance with the Creative Commons Attribution Non Commercial (CC BY-NC 4.0) license, which permits others to distribute, remix, adapt, build upon this work non-commercially, and license their derivative works on different terms, provided the original work is properly cited, appropriate credit is given, any changes made indicated, and the use is non-commercial. See: http://creativecommons.org/licenses/by-nc/4.0/.

\section{REFERENCES}

1. Liaropoulos L, Goranitis I. Health care financing and the sustainability of health systems. Int J Equity Health 2015;14:80.

2. Thomson S, Figueras J, Evetovits T, et al. Economic crisis, health systems and health in Europe: impact and implications for policy: WHO Regional Office for Europe, 2014.

3. Tello J, Baez-Camargo C. Strengthening health system accountability: a WHO European Region multi-country study. 2015.

4. Mosca I, van der Wees PJ, Mot ES, et al. Sustainability of long-term care: puzzling tasks ahead for policy-makers. Int J Health Policy Manag 2016;6:195-205.

5. Ozcan YA, Khushalani J. Assessing efficiency of public health and medical care provision in OECD countries after a decade of reform. Cent Eur J Oper Res 2017;25:325-43.

6. WRR. Weten is nog geen doen: een realistisch perspectief op redzaamheid (Dutch) (Knowing is not equal to acting: a realist view on self-reliance). Den Haag: Wetenschappelijke Raad voor het Regeringsbeleid (WRR), 2017.

7. Rademakers J. Kennissynthese: gezondheidsvaardigheden: niet voor iedereen vanzelfsprekend. NIVEL: Utrecht, 2014.

8. Starfield B. The hidden inequity in health care. Int J Equity Health 2011;10:15. 
9. Mackenbach JP, Hu Y, Artnik B, et al. Trends in inequalities in mortality amenable to health care In 17 European Countries. Health Aff 2017;36:1110-8.

10. Spencer KL, Grace M. Social Foundations of Health Care Inequality and Treatment Bias. Annu Rev Sociol 2016;42:101-20.

11. Kroneman $M$, Boerma $W$, van den Berg $M$, et al. Health systems in transition. 2016:1-239.

12. Maarse JA, Jeurissen PP. The policy and politics of the 2015 longterm care reform in the Netherlands. Health Policy 2016:120:241-5.

13. CBS. Health, lifestyle, health care use and -supply, causes of death; key figures. Secondary Health, lifestyle, health care use and -supply, causes of death; key figures. 2017 https://opendata.cbs.nl/statline/\#/ CBS/en/dataset/81628ENG/table?ts $=1528273022200$

14. CIZ. Basisrapportage AWBZ-zorg 2014. Secondary Basisrapportage AWBZ-zorg 2014. 2015 https://ciz.databank.nl/quickstep/ qsreportbasic.aspx? report=rapport\&selcode $=0.7460882087585172 \&$ geolevel=nederland\&geoitem $=1$

15. Kornalijnslijper N MK, de Klerk M, et al. Veranderde zorg en ondersteuning voor mensen met een beperking. Landelijke evaluatie van de Hervorming Langdurige Zorg (Changed care and support for people with disabilities. National evaluation of the long-term care reform. The Hague: The Netherlands Institution for Social Research (SCP), 2018.

16. van Dijk CE, Venema B, de Jong JD, et al. Market competition and price of disease management programmes: an observational study. BMC Health Serv Res 2014;14:510.

17. Mackenbach JP, Stirbu I, Roskam AJ, et al. Socioeconomic inequalities in health in 22 European countries. $N$ Engl J Med 2008;358:2468-81.

18. Moffat K, Mercer SW. Challenges of managing people with multimorbidity in today's healthcare systems. BMC Fam Pract 2015;16:129.

19. Barnett K, Mercer SW, Norbury M, et al. Epidemiology of multimorbidity and implications for health care, research, and medical education: a cross-sectional study. Lancet 2012;380:37-43.

20. O'Brien R, Wyke S, Guthrie B, et al. An 'endless struggle': a qualitative study of general practitioners' and practice nurses experiences of managing multimorbidity in socio-economically deprived areas of Scotland. Chronic IIIn 2011;7:45-59.

21. Grabovschi C, Loignon C, Fortin M. Mapping the concept of vulnerability related to health care disparities: a scoping review. $B M C$ Health Serv Res 2013;13:94.

22. Beenackers MA, Oude Groeniger J, van Lenthe FJ, et al. The role of financial strain and self-control in explaining health behaviours: the GLOBE study. Eur J Public Health 2018;28:597-603.

23. Kangovi S, Barg FK, Carter T, et al. Understanding why patients of low socioeconomic status prefer hospitals over ambulatory care. Health Aff 2013;32:1196-203.

24. Willems S, Peersman W, De Maeyer P, et al. The impact of neighborhood deprivation on patients' unscheduled out-of-hours healthcare seeking behavior: a cross-sectional study. BMC Fam Pract 2013;14:136.

25. Janssen $D$, Jongen W, Schröder-Bäck P. Exploring the impact of austerity-driven policy reforms on the quality of the long-term care provision for older people in Belgium and the Netherlands. J Aging Stud 2016;38:92-104

26. Payne RA, Abel GA, Guthrie B, et al. The effect of physical multimorbidity, mental health conditions and socioeconomic deprivation on unplanned admissions to hospital: a retrospective cohort study. CMAJ 2013;185:E221-8.

27. Löfqvist T, Burström B, Walander A, et al. Inequalities in avoidable hospitalisation by area income and the role of individual characteristics: a population-based register study in Stockholm County, Sweden. BMJ Qual Saf 2014;23:206-14.

28. Keizer E, Smits M, Peters Y, et al. Contacts with out-of-hours primary care for nonurgent problems: patients' beliefs or deficiencies in healthcare? BMC Fam Pract 2015;16:157.

29. Keizer E, Maassen I, Smits M, et al. Reducing the use of out-of-hours primary care services: a survey among dutch general practitioners. Eur J Gen Pract 2016;22:189-95

30. huisartsenposten IB. Benchmark primary OOH services 2016. InEen: Utrecht, 2016.

31. Jansen $\mathrm{T}$, Smits M, Verheij R, et al. Zorg op de huisartsenpost. Jaarcijfers 2016 en trendcijfers 2013-2016. Healthcare out-of-hours primary care service. Year report 2016 and trend analysis 2013-2016. NIVEL: Utrecht, 2016.

32. Jansen T, Zwaanswijk M, Hek K, et al. To what extent does sociodemographic composition of the neighbourhood explain regional differences in demand of primary out-of-hours care: a multilevel study. BMC Fam Pract 2015;16:1.
33. Smits M, Rutten M, Keizer E, et al. The Development and performance of after-hours primary care in the netherlands: a narrative review. Ann Intern Med 2017;166:737.

34. Van Gils-van Rooij ESJ. The paradox of urgent care collaborations: a multi perspective study of cooperating emergency departments and general practitioners: Tilburg University, 2016.

35. Huibers L, Giesen P, Wensing M, et al. Out-of-hours care in western countries: assessment of different organizational models. BMC Health Serv Res 2009;9:1.

36. Huibers LA, Moth G, Bondevik GT, et al. Diagnostic scope in outof-hours primary care services in eight European countries: an observational study. BMC Fam Pract 2011;12:30.

37. NZa. Marktscan acute zorg (Market scan acute care). Utrecht: Nederlanse Zorgautoriteit (Dutch Healthcare Authority), 2017.

38. InEen. Benchmark primary $\mathrm{OOH}$ services 2015. InEen: Utrecht, 2015.

39. Zwaanswijk M, Nielen MM, Hek K, et al. Factors associated with variation in urgency of primary out-of-hours contacts in the Netherlands: a cross-sectional study. BMJ Open 2015;5:e008421.

40. NIVEL. NIVEL Primary care database. Secondary NIVEL primary care database 2017. 2017 http://nivel.nl/en/dossier/nivel-primary-caredatabase

41. Schweikardt C, Verheij RA, Donker GA, et al. The historical development of the dutch sentinel general practice network from a paper-based into a digital primary care monitoring system. J Public Health 2016;24:545-62.

42. Kuchinke W, Ohmann C, Verheij RA, et al. A standardised graphic method for describing data privacy frameworks in primary care research using a flexible zone model. Int J Med Inform 2014;83:941-57

43. SCP. Veelgestelde vragen over de statusscores. (Frequently asked questions about status scores). Utrecht: Sociaal Cultureel Planbureau (SCP) (The Netherlands Institute for Social Research), 2012

44. Knol F, Boelhouwer J, Veldheer V. Summary Neighbourhood status development in the Netherlands 1998-2010. Secondary Summary Neighbourhood status development in the Netherlands 1998-2010. 2012 http://www.scp.nl/english/dsresource?objectid=33130\&type= org.

45. CBS. Population and households, four-digit postcode, Januari 1th, 2013 - 2016 (in Dutch: Bevolking en huishoudens: viercijferige postcode, 1 januari 2013 - 1 januari 2016). Secondary population and households, four-digit postcode, januari 1th, 2013 - 2016 (in Dutch: Bevolking en huishoudens: viercijferige postcode, 1 januari 2013 - 1 januari 2016) 1/21/2013 2014 - 2017. http://statline.cbs.nl/StatWeb/ publication/?VW=T\&DM=SLNL\&PA=81922NED\&D1=0,5,14,20,63,66, $72 \& D 2=0,15,515,2405,3612,4121,4138,4162,4164,4168,4176,4208$, $4216,4219,4294,4352,4363 \& H D=130225-1534 \& H D R=T \& S T B=G 1$

46. Cd D, Van de Stadt H, Vliegen J. Een nieuwe maatstaf voor stedelijkheid: de omgevingsadressendichtheid. Maandstatistiek van de bevolking 1992;92:14-27.

47. Cookson R, Mondor L, Asaria M, et al. Primary care and health inequality: difference-in-difference study comparing England and Ontario. PLoS One 2017;12:e0188560.

48. StataCorp. StataCorp LP. 14.0 ed: Texas, 2015.

49. Nolte E, McKee M, Evans D, et al. Saving lives? The contribution of health care to population health. In: McKee M, Figueras J, Health systems: health, wealth, society and well-being. Berkshire, England: Open University Press McGraw-Hill Education, 2011:101-24.

50. Stafford M, Duke-Williams O, Shelton N. Small area inequalities in health: are we underestimating them? Soc Sci Med 2008;67:891-9.

51. Pardo-Crespo MR, Narla NP, Williams AR, et al. Comparison of individual-level versus area-level socioeconomic measures in assessing health outcomes of children in Olmsted County, Minnesota. J Epidemiol Community Health 2013;67:305-10.

52. Galobardes B, Shaw M, Lalow DA, et al. Indicators of Socioeconomic Position. In: Oakes JM, Kaufman JS, eds. Methods in social epidemiology. San Francisco: Jossey-Bass, 2006:47-85.

53. Teirlinck A, Van Asten L, Brandsema P, et al. Annual report Surveillance of influenza and other respiratory infections in the Netherlands. the Netherlands: Winter, 2016.

54. Flinterman L, Nielen M, Verberne L, et al. Zorg door de huisarts. Jaarcijfers 2016 en trendcijfers 2011-2016. (Healthcare by the general practitioner. Year report 2016 and trend analysis 2011-2016). NIVEL: Utrecht, 2017.

55. Tuzgöl-Broekhoven A, Stam J, Atalikyayi R. Zorgen voor burgers Onderzoek naar knelpunten die burgers ervaren bij de toegang tot zorg. (Care for citizens. Study to citizen's perceived bottlenecks in accessibility of care). The Hague: National ombudsman, 2018.

56. Keizer E, Bakker P, Giesen P, et al. Migrants' motives and expectations for contacting out-of-hours primary care: a survey study. BMC Fam Pract 2017;18:92. 
57. Heijmans M, Uiters E, Rose T, et al. Study on sound evidence for a better understanding of health literacy in the European Union: European Commission Brussels, 2015.

58. Schols AM, van Boekholt TA, Oversier LM, et al. General practitioners' experiences with out-of-hours cardiorespiratory consultations: a qualitative study. BMJ Open 2016;6:e012136.

59. Drummond N, McConnachie A, O'Donnell CA, et al. Social variation in reasons for contacting general practice out-of-hours: implications for daytime service provision? Br J Gen Pract 2000;50:460-4.
60. Freeman G, Hughes J. Continuity of care and the patient experience. London: The King's Fund, 2010.

61. Salisbury C, Johnson L, Purdy S, et al. Epidemiology and impact of multimorbidity in primary care: a retrospective cohort study. $\mathrm{Br} J$ Gen Pract 2011;61:e12-21.

62. Ilinca $S$, Rodrigues R, Schmidt AE. Fairness and eligibility to longterm care: an analysis of the factors driving inequality and inequity in the use of home care for older Europeans. Int J Environ Res Public Health 2017;14:1224. 